\title{
Hydrogen Absorption/Desorption Behavior of a Cold-Rolled TiFe Intermetallic Compound
}

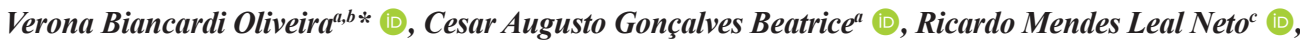 \\ Wágner Batista Silva ${ }^{a}$ (D) Luiz Antonio Pessan ${ }^{a}$,Walter José Botta ${ }^{a}$, Daniel Rodrigo Leiva ${ }^{a}$ \\ ${ }^{a}$ Universidade Federal de São Carlos, Departamento de Engenharia de Materiais, Programa de \\ Pós-Graduação em Ciência e Engenharia de Materiais, São Carlos, SP, Brasil. \\ ${ }^{b}$ Universidade do Estado do Rio de Janeiro, Instituto Politécnico, Departamento de Engenharia de \\ Materiais, Nova Friburgo, RJ, Brasil. \\ 'Instituto de Pesquisas Energéticas e Nucleares, Centro de Ciência e Tecnologia de Materiais, São \\ Paulo, SP, Brasil.
}

Received: April 29, 2021; Revised: July 12, 2021; Accepted: September 05, 2021

The (de)hydrogenation properties of a TiFe intermetallic compound (IMC) alloy activated by cold rolling inside a glovebox at ambient temperature were investigated by kinetic measurements, $\mathrm{x}$-ray powder diffraction (XRD), and transmission electron microscopy (TEM). Rate-limiting steps were identified by testing kinetic models on hydrogen absorption and desorption curves. To prevent surface poisoning during air exposure, the TiFe IMC was also cold rolled with polytetrafluoroethylene (PTFE) and ultra-high molecular weight polyethylene (UHMWPE). The addition of either PTFE or UHMWPE to nanostructured TiFe by cold rolling did not produce a polymer-metal composite with $\mathrm{O}_{2}$ poisoning resistance, regardless of the polymer-mixing way adopted. This occurred because large surfaces of the particles were not adequately coated with polymer. The results identify challenges to the TiFe IMC polymer-covered material that must be overcome before a methodology can significantly contribute to the formation of nanostructured TiFe-polymer composites with enhanced hydrogen storage properties. The diffusion-controlled reactions in the cold-rolled TiFe IMC without polymer were prevalent in all cases, as predicted by the Jander three-dimensional diffusion model. The main contribution of this work regards estimation of the amount of hydrogen released, which was $0.60 \%$ after $6 \mathrm{~min}$ and reproducible for the three subsequent cycles.

Keywords: Nanostructured TiFe, cold rolling, (de)hydriding behaviors, modeling, polymer covering.

\section{Introduction}

The TiFe intermetallic compound (IMC) is a low-cost material of great interest to hydrogen storage in the solid-state due to its theoretical hydrogen storage capacity (1.9 wt.\%) at ambient temperature. However, if manufactured only by casting, the TiFe IMC does not absorb hydrogen, unless further processed by some deformation method responsible for producing nanometer-sized microstructures ${ }^{1-4}$. Nanostructured TiFe alloys can react highly, exothermically and reversibly, with hydrogen at ambient temperature to form hydrides of the approximate compositions: $\mathrm{TiFeH}$ and $\mathrm{TiFeH}_{2}^{5-8}$. In this case, the hydrogen capacity of nanostructured TiFe can reach up to $\sim 1.4 \mathrm{wt} . \%$ in practice ${ }^{9}$, but only under inert atmosphere, since its first hydrogenation process is heavily impaired by air contamination ${ }^{10,11}$. To overcome this problem, a systematic repetition of several thermal cycles that involves previously heating the TiFe IMC to $\sim 400{ }^{\circ} \mathrm{C}$ under vacuum ${ }^{5,12-17}$ must be employed ${ }^{3}$.

Many researchers have studied the first hydrogen absorption in nanostructured TiFe without thermal activation $^{2,8,18-33}$. Two main strategies have been employed

*e-mail: ver.bia.oli@gmail.com to solve the activation problem of TiFe IMC. One of them is based on chemical methods through addition of $\mathrm{Mn}$ or $\mathrm{Zr}$ to TiFe IMC; the mechanism of activation is attributed to surface activation and easy hydrogen dissociation. A second strategy is based on mechanical methods - ball milling, rolling, and high-pressure torsion, whose activation mechanisms are attributed to hydrogen diffusion through microstructural pathways. Thus, these methods provide a way to mechanically (re-)activate hydride-forming materials via microstructural modifications (such as grain refinement process) that enhance the pathways to diffuse the hydrogen atoms within the material. The target of both strategies is to handle the material in air, and not under inert gas or vacuum.

Manna et al. ${ }^{24}$ prepared TiFe IMC with $4 \mathrm{wt} \% \mathrm{Zr}$ using an induction melting process - crushing it and exposing it to air for seven days, and observed that a secondary $\mathrm{Zr}$-rich phase in the alloy enabled its activation by ball milling and cold rolling. This secondary phase acts as a gateway for hydrogen, and probably does not oxidize as easily as the TiFe IMC itself. Edalati et al. ${ }^{34}$ processed TiFe IMC using groove rolling and observed that surface segregation is not essential for activation by plastic deformation. Still, the 
formation of sub-grain and grain boundaries and cracks that act as pathways to transport hydrogen through the oxide layer is the main reason for activation.

Vega et al. $^{2}$ evaluated the cold rolling process under inert atmospheres as a mechanical activation route of stoichiometric TiFe prepared by arc melting. The ingot was ground and then cold rolled up to 20 and 40 passes. Coldrolled samples exhibited rapid hydrogen absorption during the first hydrogenation at ambient temperature and without any previous thermal reactivation process. This was attributed to the crystalline defects introduced to the microstructure of the TiFe IMC that could act efficiently on the clean surface, with no poisoning effects. The main result of that study is that the cold rolling process provided excellent hydrogen absorption kinetics of the stoichiometric TiFe compared with other severe plastic deformation (SPD) techniques ${ }^{4,8}$.

However, to the best of our knowledge, there are no reports in the literature evaluating in detail the dehydrogenation kinetics of nanostructured TiFe intermetallic alloys. Few studies have determined the discharge capacity and cycle life of nanocrystalline TiFe electrodes ${ }^{29,30}$. Recognizing this, we measured the (de)absorption kinetics of the TiFe IMC activated by cold rolling under a protective atmosphere. We also identified the rate-limiting step for transformation kinetics by fitting analytical rate expressions (from kinetic models) to the experimental data.

It is worth mentioning that even if the cold rolling processing route is a powerful tool to reduce the activation time and costs for hydride metallic alloys, the nanostructured TiFe obtained by this technique is reported, as previously mentioned, to not resist surface poisoning by the contaminants present in the air $^{35}$. Thus, the addition of specific polymers to hydride-forming metal powders has been the subject of some experimental studies that aimed to produce nanostructured metal-polymer composite materials with the potential of simultaneously react with hydrogen and resist surface poisoning. This ensures good mechanical stability, high thermal conductivity, fast kinetics, reproducibility, and durability to these composites ${ }^{36-42}$. Various polymeric materials have been considered in that respect, among which PTFE and ABS stand out as candidates that can offer prominent advantages. In these cases, the preparation procedure of such nanostructured metal-polymer composites usually involves high-energy ball milling (HEBM $)^{40-42}$. HEBM is responsible for the mechanical activation of the powder and the deposition of the polymer on its activated surfaces together with the mixture homogenization. However, the preparation of such nanocomposites based on the HEBM technique is expensive and time-consuming. Recognizing the role of surface in the reactivity of metallic materials with hydrogen and the impurities present in the air, this investigation includes an analysis of the use of the cold rolling process to produce nanostructured TiFe with polymer covering in an attempt to improve its resistance to air.

\section{Experimental Details}

\subsection{Preparation of the TiFe alloy}

A TiFe IMC alloy with a composition of $50 \mathrm{wt} . \% \mathrm{Fe}$ and $50 \mathrm{wt} . \% \mathrm{Ti}$ was produced by melting in an arc furnace under argon atmosphere. The loaded materials were re-melted five times and turned on their opposite sides without opening the chamber, resulting in $15 \mathrm{~g}$ of homogenized bulk material.

\subsection{Cold rolling of the TiFe IMC alloy}

The cast material was hand broken under air using a mortar and pestle to produce pieces with largest average particle size of $\sim 6 \mathrm{~mm}$. The cold rolling processing of these pieces was vertically conducted on a homemade experimental rolling mill composed of two rolls made of tool steel $(6.4 \mathrm{~mm}$ in diameter and $8 \mathrm{~cm}$ length) placed inside a glovebox (MBRAUN LAB Master 130). The TiFe IMC alloy pieces were subjected to cold rolling aiming to produce nanostructured TiFe powder under both inert and air atmospheres. The polymer protection was applied to the TiFe IMC alloy powder by the cold rolling process only under inert atmosphere (inside the glovebox).

Initially, the amount of $500 \mathrm{mg}$ of TiFe IMC pieces was placed between the rolls with a distance of $\sim 6 \mathrm{~mm}$ between them and cold rolled with gradual approach of the rolls until they touch each other (i.e., reaching the minimum distance). Once the powder was formed (after reaching the minimum distance between the rolls), the cold rolling was performed up to 20 deformation passes. All steps were conducted at $50 \mathrm{rpm}$. The TiFe IMC powders were collected from a compartment located below the vertical rolls of the mill. The level of oxygen incorporation into the nanostructured TiFe powder produced under air atmosphere (and its deleterious effect on its reactivity with hydrogen) was evaluated by chemical analysis using an elemental analyzer ONH836 (Leco).

The cold rolling technique was also used to cover the TiFe powder with polytetrafluoroethylene (PTFE) and ultra-high molecular weight polyethylene (UHMWPE). PTFE and UHMWPE were selected as inert binders because of their different temperatures of physical and chemical stability, physisorption characteristics, and protection against oxidation $^{39-42}$. The polymer powder was added to the TiFe IMC through the cold rolling route in the same experimental rolling mill and under both atmospheres (argon and air) in two ways: (a) since the beginning of the cold rolling processing, that is, simultaneously with the TiFe IMC pieces, and (b) after the TiFe IMC pieces were cold rolled. The latter was performed to mix and compact the polymer material to the nanostructured TiFe powder using a few rolling passes. In all cases, the polymer and the TiFe IMC materials were weighed in the proportion of 30:70 wt.\%, respectively, with $70 \%$ mass corresponding to $500 \mathrm{mg}$ of metal alloy. The samples produced inside the glove box were placed in the reactor of the Sieverts apparatus outside the glove box to verify the cover efficiency in terms of hydrogen absorption and air poisoning.

\subsection{Characterization of the TiFe IMC alloy with and without polymer covering}

Phase analysis was conducted by X-ray powder diffraction (XRD) in a Siemens D5005 diffractometer with $\mathrm{Cu}-\mathrm{K} \alpha$ radiation at $40 \mathrm{kV}$ and $40 \mathrm{~mA}$. The collected data were processed using the X'Pert HighScore Plus software. The coldrolled nanostructured TiFe was examined by transmission electron microscopy (TEM) using the field emission gun 
(FEG) equipment (FEI Tecnai $\mathrm{G}^{2}$ F20) at $200 \mathrm{kV}$. The TiFe IMC was also analyzed by optical microscopy (OM) in an Olympus optical microscope, model BX41M/2ED, with a polarizing filter. The samples were prepared by hot embedding with Bakelite in granulated powder form, sanding, and automatic polishing, using \#1200 and \#2000 sandpaper and $1 / 4 \mu \mathrm{m}$ diamond paste. The surfaces were etched in a solution of $15 \mathrm{~mL} 5 \% \mathrm{Nital}+4 \mathrm{~mL} \mathrm{HCl}+10 \mathrm{~mL} \mathrm{FeCl}_{3}$ for $1 \mathrm{~min}$ and then cleaned with methyl alcohol under a hot air jet. Scanning electron microscopy (SEM) analysis was carried out in the Philip XL-30 FEG microscope equipped with energy dispersive $\mathrm{x}$-ray spectrometry (EDS) to evaluate the particle size, microstructure defects, and surface features of the particles and to understand the effectiveness of the polymer covering applied through the cold rolling route. The alloy particles were added to ethanol and dropped onto a sample holder.

\section{4. (De)hydrogenation measurements}

Hydrogenation and dehydrogenation data of the coldrolled nanostructured TiFe IMC, with and without polymer covering, were obtained using a homemade Sieverts-type apparatus installed in the Metal Hydrogen Laboratory (LH2M) at the Federal University of São Carlos (UFSCar). Kinetic measurements were performed at room temperature under hydrogen (20 bar) for the absorption cycles and vacuum (0.07 bar) for the desorption cycles.

Kinetic experimental data were used to identify the ratelimiting step of the hydriding and dehydriding reactions in the cold-rolled TiFe IMC. The slowest step can be deduced by fitting the data with the analytical expression of the various kinetic models listed in Table 1. Good reviews describing kinetic models have already been published ${ }^{43-45,47-50}$. The classical model designation ${ }^{45}$, as well as a more identifiable designation, adopted before by Lang et al. ${ }^{51}$, are given in Table 1 . The best-fitted model indicates the most probable limiting step. A widespread and most straightforward procedure to find this out ${ }^{51,52}$ is to arrange the model equations by leaving, on the left side, a function of the reacted fraction $\alpha$, which ranges from 0 (at the beginning of reaction) to 1 (maximum attained sample capacity). The right side of all equations is $k t$ : where $k$ is the reaction constant and $t$ is the reaction time. The best-fitted model then gives a straight line, and the fitness quality can be measured by the squared correlation coefficient $R^{2}$, calculated in the regression analysis by the least-squares method.

\section{Results and Discussion}

\subsection{Microstructure characterization of cold- rolled TiFe IMC without polymer covering}

The XRD patterns of the TiFe IMC alloy before and after cold rolling are shown in Figure 1. The patterns only show peaks belonging to the TiFe IMC cubic phase ( $\mathrm{Pm}-3 \mathrm{~m}$ space group) for both conditions. The cold rolling process causes the XRD peaks to reduce in intensity with the disappearance of the two small peaks around 30 and $71^{\circ}$, which agrees with the larger amount of powder particles produced through

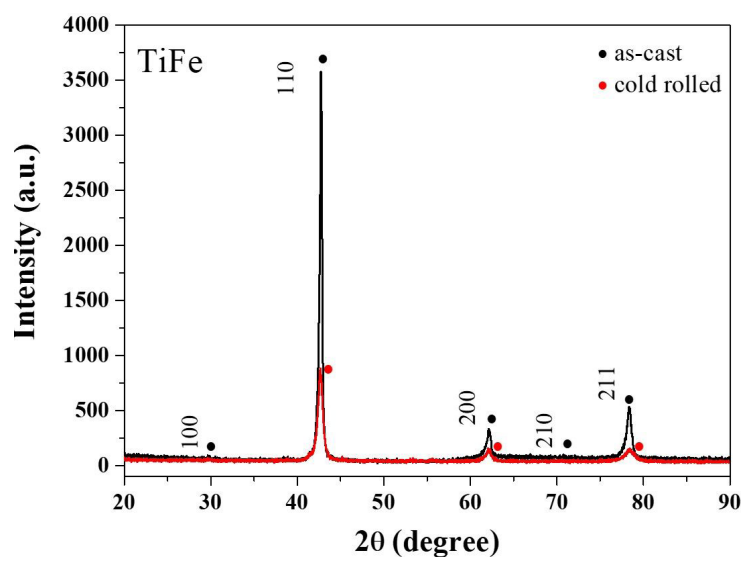

Figure 1. XRD spectra of the TiFe IMC alloy in the as-cast and cold-rolled conditions.

Table 1. Equations used for fitting the experimental sorption data ( $\alpha$ is the reacted fraction as defined in the text)

\begin{tabular}{cccl}
\hline $\begin{array}{c}\text { Integral form of the } \\
\text { kinetics model: } \\
\mathrm{g}(\alpha)=k t\end{array}$ & $\begin{array}{c}\text { Classical model } \\
\text { designation }\end{array}$ & $\begin{array}{c}\text { Current model } \\
\text { designation }\end{array}$ & \multicolumn{1}{c}{ Description } \\
\hline$\alpha$ & R1 & Chemisorption & Surface controlled; one-dimensional interface reaction ${ }^{43,44}$ \\
\hline $1-(1-\alpha)^{1 / 2}$ & R2 & CV-2D: & $\begin{array}{l}\text { Contracting volume; two-dimensional growth with constant } \\
\text { interface velocity }\end{array}$ \\
\hline $1-[1-\alpha]^{43,45}$ & CV-3D & $\begin{array}{l}\text { Contracting volume; three-dimensional growth with constant } \\
\text { interface velocity }\end{array}$ \\
\hline$(1-\alpha) \ln (1-\alpha)+\alpha$ & R3 & GB-2D: & $\begin{array}{l}\text { Ginstling-Brounshtein; two-dimensional growth, diffusion- } \\
\text { controlled with decreasing interface velocity }\end{array}$ \\
\hline $1-(2 \alpha / 3)-(1-\alpha)^{2 / 3}$ & D4 & GB-3D: & $\begin{array}{l}\text { Ginstling-Brounshtein; three-dimensional growth, diffusion- } \\
\text { controlled with decreasing interface velocity }\end{array}$ \\
\hline$\left[1-(1-\alpha)^{1 / 3}\right]^{2}$ & D3 & Jander: & $\begin{array}{l}\text { Jander; constant volume, diffusion-controlled with constant } \\
\text { diffusion interface area }{ }^{43,45}\end{array}$ \\
\hline$[-\ln (1-\alpha)]^{1 / 2}$ & A2 & JMA-2D: & $\begin{array}{l}\text { Johnson-Mehl-Avrami; two-dimensional growth of existing nuclei } \\
\text { with constant interface velocity }\end{array}$ \\
\hline$[-\ln (1-\alpha)]^{1 / 3}$ & A3 & JMA-3D & $\begin{array}{l}\text { Johnson-Mehl-Avrami; three-dimensional growth of existing } \\
\text { nuclei with constant interface velocity } 43,45\end{array}$ \\
\hline
\end{tabular}


the cold rolling route ${ }^{53}$. The strain associated with the sample cold work leads to micro-stresses responsible for the broadening of the experimental diffraction peaks of the cold-rolled TiFe IMC ${ }^{53-57}$.

Optical microscopy and SEM observations of the TiFe IMC alloy in the as-cast and cold-rolled conditions are given in Figure 2. Grains in the bulk cast alloy are equiaxed with a mean size of $\sim 500 \mu \mathrm{m}$, as shown in Figure $2 \mathrm{a}$. By cold rolling, slightly porous agglomerated powder particles were produced from the bulk material, as illustrated in Figure $2 b$. In Figure 2c, the agglomerated powder particles can be observed at greater magnification, and show individual irregular sub-micrometric particles. The surface SEM image of these agglomerated powder particles is shown in Figure 2d, where many cracks with a length of a few micrometers developed after the TiFe IMC was cold-rolled can be observed.

TEM observation confirms that the cold rolling process produced powder particles in the range from about 200 to $500 \mathrm{~nm}$, as shown in Figure 3a. The grain size evaluated from the TEM micrograph at higher magnification is confirmed to be $\sim 10 \mathrm{~nm}$, as shown in Figure $3 \mathrm{~b}$. The electron diffraction pattern presented in Figure $3 \mathrm{c}$ is a cubic $\mathrm{CsCl}$ type $\mathrm{TiFe}$ IMC structure.

\subsection{Hydrogen storage behavior of cold-rolled TiFe IMC without polymer covering}

Once the samples were activated by cold rolling, they could be cyclically hydrogenated. The absorption and desorption curves of the cold-rolled nanostructured TiFe IMC are shown in Figure 4a, where cycle 1 corresponds to the first absorption/desorption measurement performed immediately after the mechanical activation procedure. In the present case, determination of the optimal cut-off value on the datasheet was inaccurate due to an error in the equipment pressure sensors, which corresponds to a pressure variation of \pm 0.15 bar. Any value measured within that cannot be associated with variations in the material hydrogen storage properties. Therefore, as the largest difference between either absorption or desorption measurements found here was \pm 0.14 bar (Figure $4 b$ ), this was considered within the

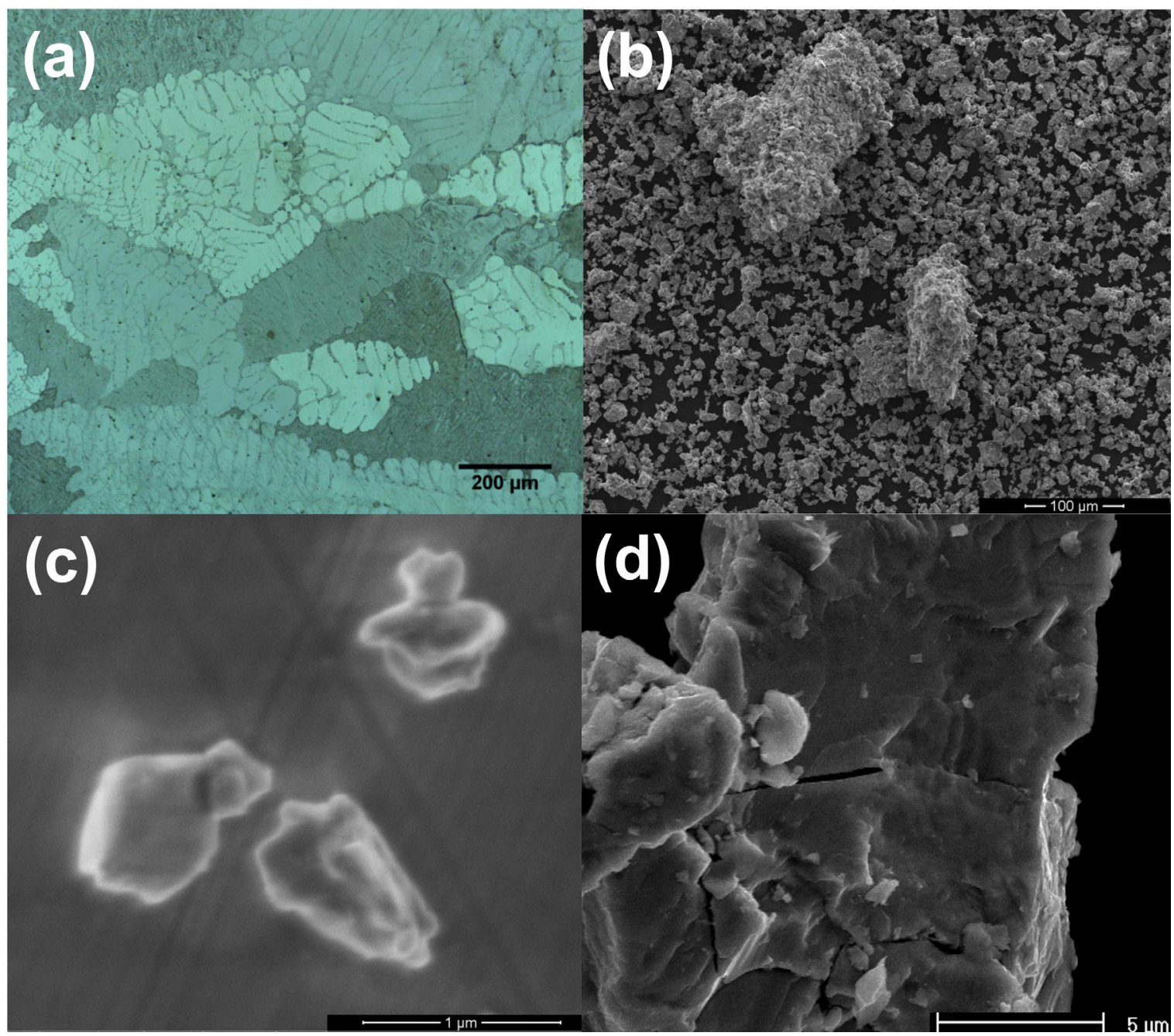

Figure 2. (a) Optical microscopy of the TiFe IMC alloy as-cast (bulk) and (b), (c), and (d) SEM microstructures with magnification of 200x, 100,000x, and 500x, respectively, of the particles formed by cold rolling. 


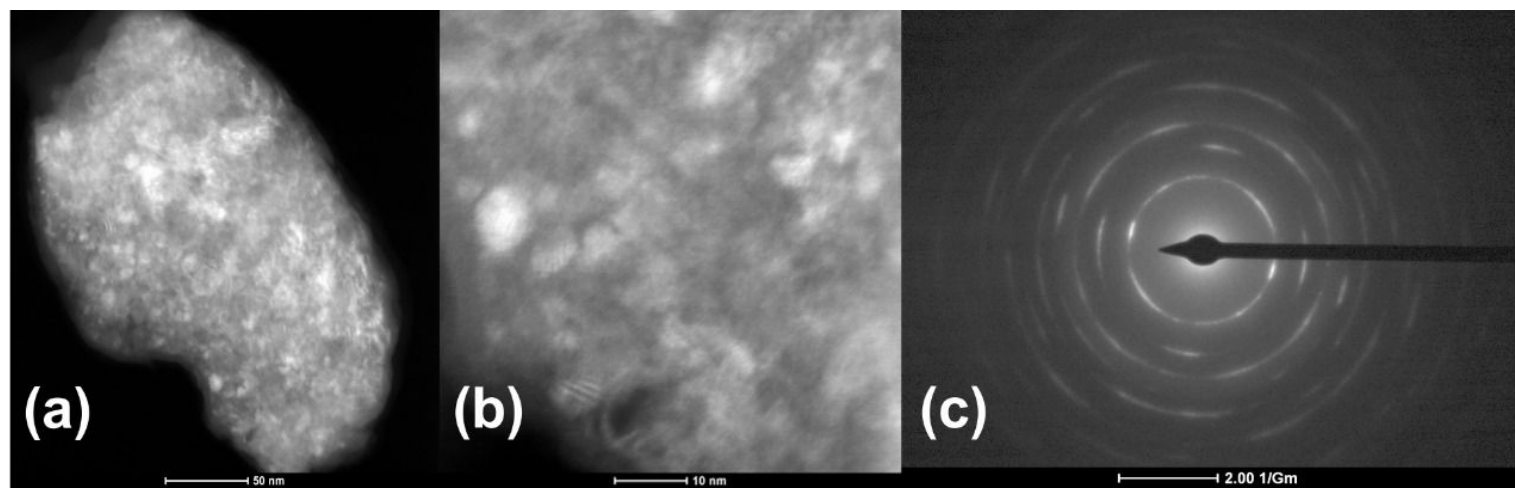

Figure 3. TEM observation of the cold-rolled TiFe IMC alloy: (a) dark-field image of an individual nanometer-sized particle; (b) grain size of 'a' shown at higher magnification, (c) corresponding the SAED pattern ([110], [200], and [211]).

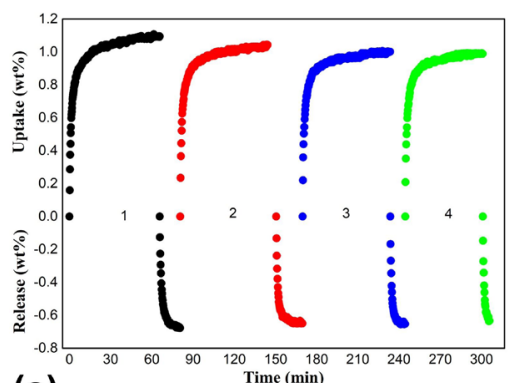

(a)

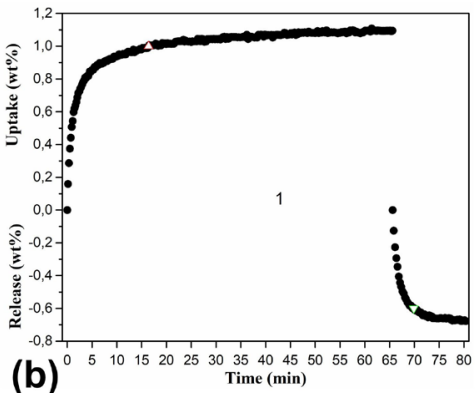

(b)

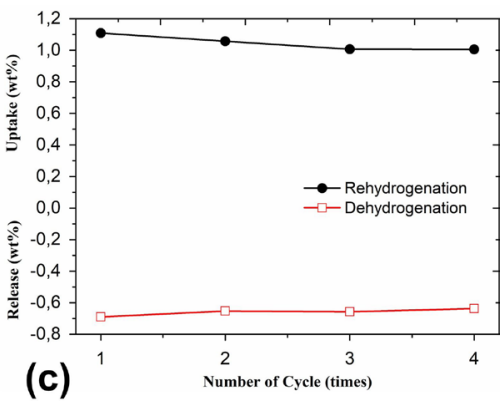

(c)

Figure 4. (a) (De)hydrogenation kinetics of the first four cycles, (b) first cycle presented in more detail, and (c) amount of absorbed and released hydrogen as a function of the number of cycles at ambient temperature under 20-bar hydrogen pressure of the cold-rolled TiFe IMC alloy.

acceptable error in the equipment sensors. Thus, it is assumed that all experimental curves obtained either for the absorption or for the desorption process during the measurements can be considered equivalent, that is, they reproduce similar capacity and kinetics behaviors, as shown below.

It is possible to observe that the cold-rolled TiFe IMC shows no incubation time and readily absorbs hydrogen, as already shown by Vega et al. ${ }^{2}$. The alloy absorbs $\sim 1.0 \mathrm{wt} \%$ hydrogen after $45 \mathrm{~min}$ (see the red point in Figure $4 \mathrm{~b}$ at ambient temperature under an initial hydrogen pressure of 20 bar; however, most of the hydrogen is absorbed within the first $8 \mathrm{~min}$ of reaction. Our results agree with those reported by Vega et $\mathrm{al}^{2}$, who also found quick hydrogen absorption kinetics for TiFe IMC alloy after its activation by cold rolling under inert atmosphere. Haraki et al. ${ }^{31}$ also found 0.9 and $1.4 \mathrm{wt} \%$ hydrogen, respectively, for the $1^{\text {st }}$ and $2^{\text {nd }}$ hydrogen absorptions within $50 \mathrm{~min}$ in equiatomic TiFe IMC samples processed by mechanical alloying (MA) and mechanical grinding (MG) for $2 \mathrm{~h}$. Most references on hydrogen storage in nanostructured TiFe IMC report hydrogen uptake capacity from $0.9^{31}$ to $1.9 \mathrm{wt} \%$ at ambient temperature and pressures from 5 to $20 \mathrm{bar}^{31}$. The powder particle surface and the inert atmosphere greatly influence hydrogen absorption properties, regardless of the hydrogen absorption cycle. Although the most agglomerated TiFe IMC powder particles have particle sizes of several microns, they have a highly developed surface area (cracks and nanosize grains) that provide good hydrogenation properties.

During dehydrogenation, the alloy can release up to $0.60 \mathrm{wt} \%$ hydrogen after only $2.5 \mathrm{~min}$ (see the open symbol in Figure 4b. At this point, the alloy slows down the rate of further dehydrogenation and takes another $5.5 \mathrm{~min}$ to release a total of $\sim 0.65 \mathrm{wt} \%$ hydrogen. A small difference between the amounts of absorbed and desorbed hydrogen could be due to loss of information that was not saved. The dehydrogenation process under vacuum ( 0.1 bar) is very fast in the TiFe IMC. A small hydrogen amount may be retained in the alloy after each dehydrogenation cycle as a result of the low hydrogen pressure plateau at ambient temperature for the TiFeH hydride. Thus, the smaller hydrogen amount released compared with that absorbed for each cycle could be attributed mainly to hydrogen retention in the alloy (the amount of retained hydride is insufficient to be detected by XRD). Although the dehydrogenation data are difficult measure, such findings are of particular importance because there is no previous research (to our knowledge) on desorption behavior using particle size distribution (PCT) measurements on the TiFe IMC alloy. A literature survey shows that many experimental data sets of the activation process have been collected and studied for the nanostructured TiFe IMC alloy, and useful processing routes have been proposed; however, they lack dehydrogenation kinetics results. Thus, our findings present a 
reasonable basis for understanding dehydrogenation kinetics and its mechanism in the nanostructured TiFe IMC alloy.

\subsection{Kinetics modelling of the hydrogenation of TiFe IMC without polymer covering}

Figures 5 and 6 present plots of the equations presented in Table 1 as a function of the reacted fraction $(\alpha)$ for the first and fourth hydrogen absorption/desorption cycles. Linear fitting curves are also shown, and were calculated from 10 to $90 \%$ of the reacted fraction to avoid the effect of the transient period at the beginning and end of reaction. Table 2 shows the adjusted $R^{2}$ values (correlation coefficients) of the curves shown in Figures 5 and 6.

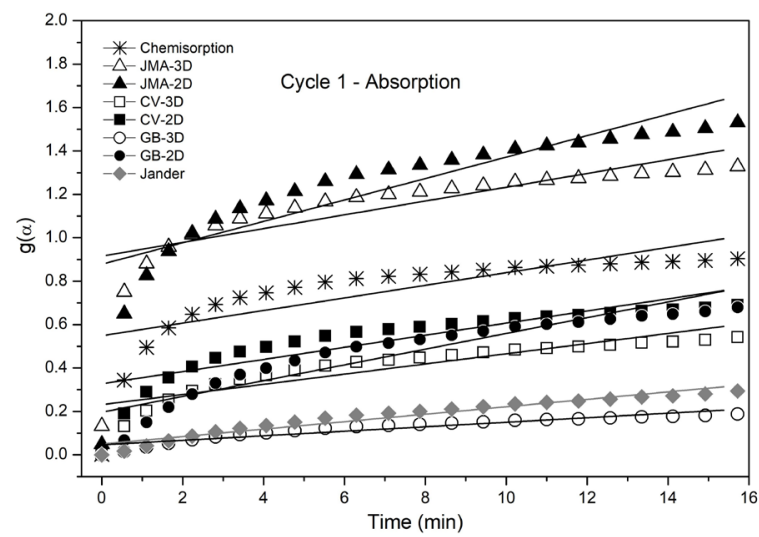

Figures 5 and 6 show that the Jander, GB-3D and GB2D models always best fitted the experimental data from the four samples. The Jander model, however, always has higher adjusted $R^{2}$ values, as shown in Table 2 . The ratelimiting step has then not changed with cycling, despite the variations in the adjustment. It was clear that the adjustment was better on desorption than adsorption, but the reason for that was not clear at this time. In other reports on TiFe IMC alloys, $R^{2}$ values ranged from $0.946^{58}$ to $0.996^{59}$. Therefore, the adjustment from this study can be considered good. Analysis of Table 2 also shows that there was a systematic decrease in the adjustment quality from cycles 1 to 4 . This

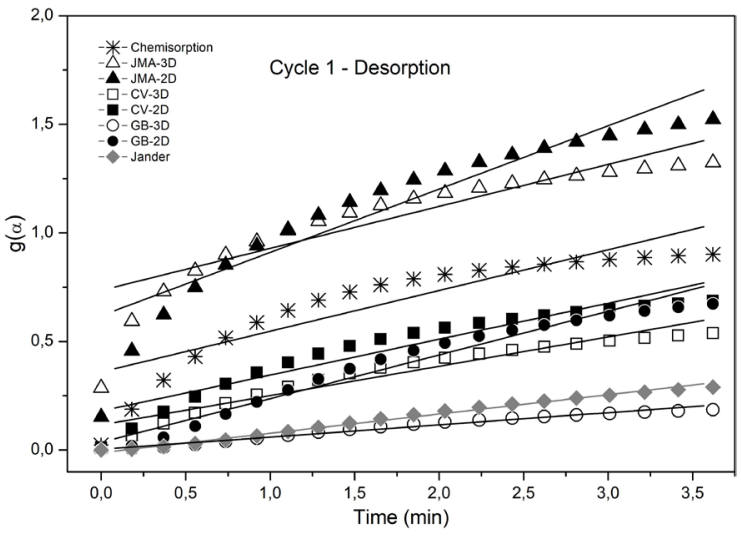

Figure 5. Linear fitting of the rate-limiting step models for the first hydrogenation and dehydrogenation of cold-rolled TiFe IMC.
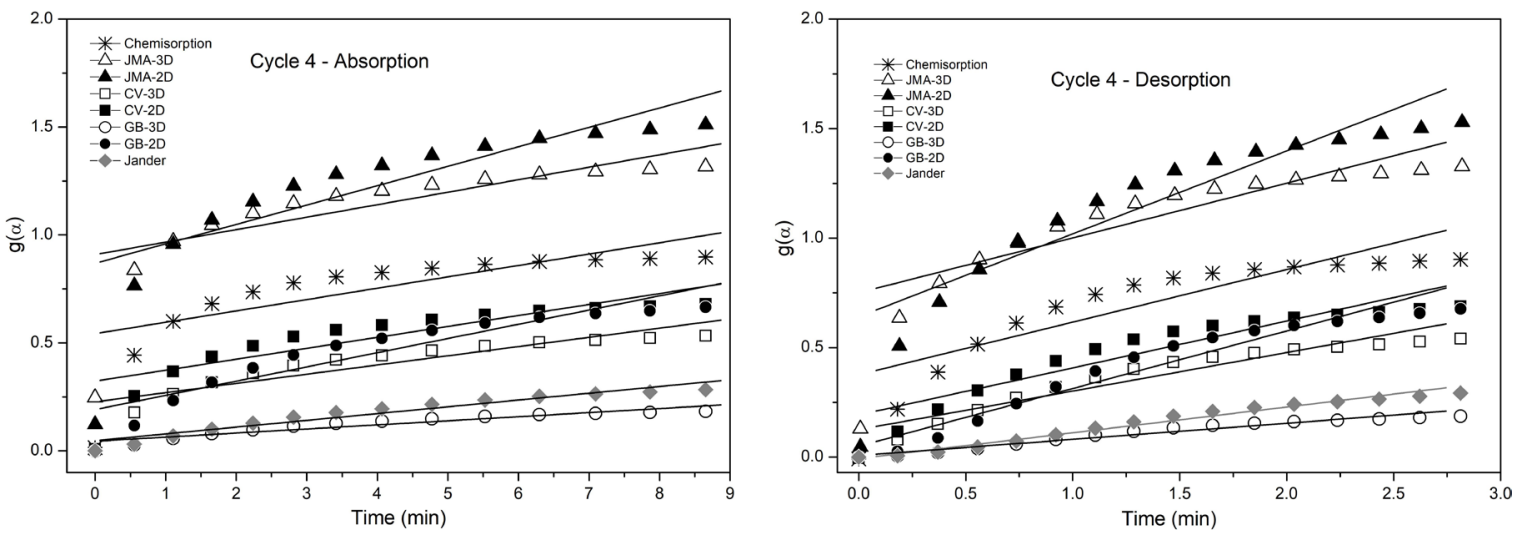

Figure 6. Linear fitting of the rate-limiting step models for the fourth hydrogenation and dehydrogenation of cold-rolled TiFe IMC.

Table 2. Adjusted $R^{2}$ values for absorption and desorption rate-limiting step model regressions

\begin{tabular}{ccccc}
\hline Model & Cycle 1 (absorption) & Cycle 1 (desorption) & Cycle 4 (absorption) & Cycle 4 (desorption) \\
\hline Chemisorption & 0.67634 & 0.82872 & 0.67218 & 0.79711 \\
\hline CV-2D & 0.79834 & 0.91497 & 0.79479 & 0.88520 \\
\hline CV-3D & 0.83503 & 0.93859 & 0.83162 & 0.91041 \\
\hline GB-2D & 0.86978 & 0.96312 & 0.86461 & 0.93461 \\
\hline GB-3D & 0.89828 & 0.97686 & 0.89309 & 0.95141 \\
\hline Jander & $\mathbf{0 . 9 4 2 1 2}$ & $\mathbf{0 . 9 9 3 0 8}$ & $\mathbf{0 . 9 3 6 9 1}$ & 0.97489 \\
\hline JMA-2D & 0.80655 & 0.91400 & 0.80381 & 0.88684 \\
\hline JMA-3D & 0.76524 & 0.88174 & 0.76240 & 0.85448 \\
\hline
\end{tabular}


can be a result of some amount of hydrogen retained in the host material with cycling, as previously mentioned.

The three previous models are based on diffusioncontrolled reactions and assumed a decreasing interface velocity as the reaction progresses ${ }^{50}$. In contrast, the Jander model (or D3) ${ }^{60}$ assumed a constant diffusion interface area for a spherical particle, which overestimated the area. The Ginstling-Brounshtein models (GB-3D or D4, and GB-2D or D2) removed that assumption. Despite that, the best fitting values obtained here cannot be disregarded. Actually, the Jander model can be used in practice for small particles, since they can meet the assumptions of this model $^{50}$. It has been previously observed ${ }^{4}$ that the absorption kinetics of ball-milled TiFe IMC is also best fitted by the Jander model. In other investigations conducted on TiFe IMC with additives ${ }^{58,59}$, the GB-3D model was best fitted to the data. However, the Jander model was not considered by those authors. In other hydrogen storage systems, such as nanocrystalline Ti-catalyzed $\mathrm{MgH}_{2}{ }^{61}$ and La-based metal hydride $^{62}$ alloys, the Jander model closely matched the reaction kinetics data.

It is worth mentioning that, one of the variants of the Chou model ${ }^{63}$, not tested here, which deals with the diffusion of hydrogen, is mathematically equivalent to the Jander model, which makes the use, or not, of this model a controversial issue. Further investigations are underway to clarify this issue, and will be the subject of a future work.

\subsection{Evaluation of covering cold rolled TiFe with polymeric materials}

Due to the evaluated degree of oxygen incorporation, PTFE and UHMWPE were added to the TiFe IMC processed by cold rolling under inert and air atmospheres. The objective was to assess the possibility of avoiding the poisoning of the nanocrystalline TiFe IMC alloy, allowing its use in a more practical way - that is, without the need for an inert atmosphere - for hydrogen storage. After addition of the polymers, a reduction in the effect of air exposure on $\mathrm{H}_{2}$ sorption kinetics of the alloy was expected; the hydrogen does not react with the polymer molecules, but it can permeate easily through them ${ }^{64}$.

SEM images of the PTFE- and UHMWPE-TiFe IMC composites fabricated using (1) polymer deposition simultaneously with the TiFe IMC pieces (regardless of the environment), or (2) polymer deposition after the TiFe IMC pieces were cold rolled under air are omitted here. According to the unfavorable results obtained in those cases, it was decided that only the composites developed using polymer addition after the TiFe IMC pieces had been cold rolled under inert atmosphere would be evaluated. Thus, top and cross-sectional SEM images (BSE mode) of the PTFE- and UHMWPE-TiFe IMC composites produced under such conditions are displayed in Figures 7 and 8, respectively. It was impossible to collect images from the cross-section of the UHMWPE-TiFe IMC composite due to its fragility.

Thus, the composites are thin-film sheets of TiFe IMC particles (bright areas) embedded in the polymer material

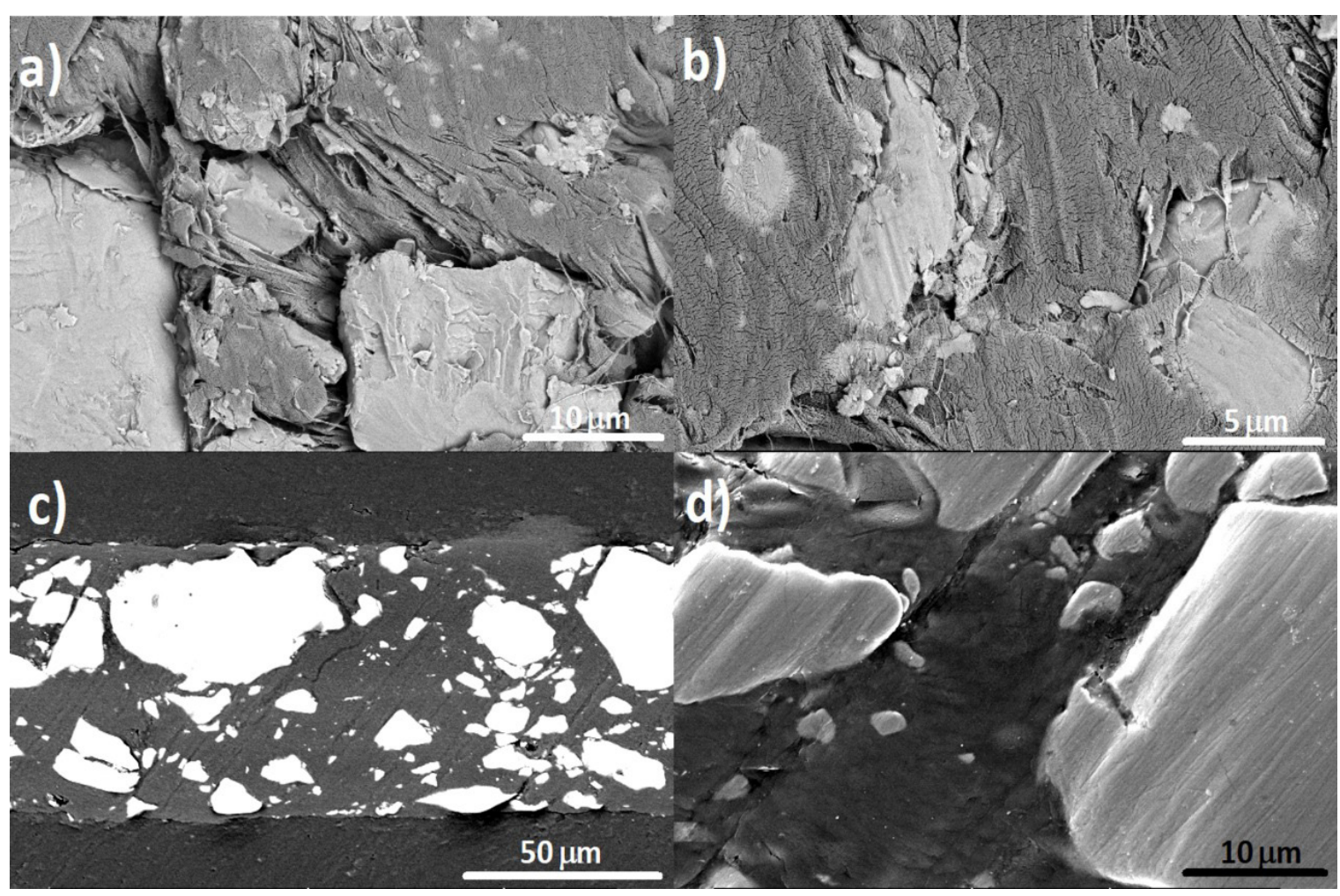

Figure 7. SEM image (BSE mode) of the (a-b) top and (c-d) cross-section of the PTFE-TiFe IMC composite. 


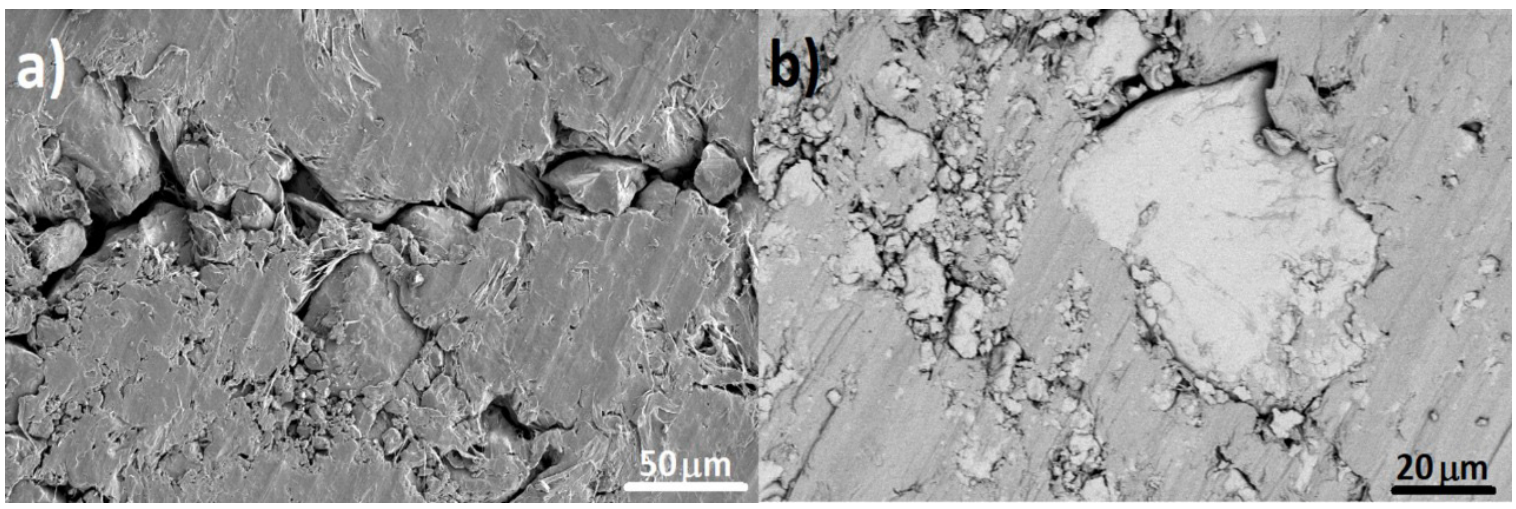

Figure 8. SEM image (BSE mode) of the top cross-section of the UHMWPE-TiFe IMC composite. Magnification of (a) 500x and (b) 1000x.

(dark areas). However, poor interfacial adhesion of the polymer to the TiFe IMC particles is verified from the top view, regardless of the employed polymer material. Excessive deformation of the polymer was responsible for its rupture and the exposure of the TiFe IMC particles. From the cross-section view, the particles were covered adequately throughout the thickness, but those near the surface are also partially exposed to air. It was observed that none of the composites absorbed hydrogen because of the immediate poisoning of the TiFe IMC particles when in contact with air. The same conclusion emerged for the UHMWPE-TiFe IMC composite, as shown in Figure 8. In both cases, the oxygen level measurements were not carried out because the polymers could damage the LECO equipment. Although the results are not promising, they assist in understanding the limited effectiveness of the cold rolling process to incorporate protective polymer covering onto TiFe IMC. To address the issue of covering TiFe IMC particles, the possibility of using a hot-press mold and efficiently blend the alloy particles with the polymer may be experimentally assessed.

\section{Conclusions}

Hydrogen desorption kinetics at room temperature, which has not been reported before, and hydrogen absorption kinetics were measured for a cold-rolled TiFe IMC alloy processed under inert atmosphere. Cold rolling was successful in activating the samples that were prone to absorb hydrogen without additional thermal treatments. The samples exhibited fast hydrogenation/dehydrogenation kinetics, mainly attributed to the cracks on the surface of powder particles and to refined grain sizes. Absorption/ desorption capacities reached approximately 1.1 and $0.7 \mathrm{wt} \%$ hydrogen, respectively. The Jander diffusion model, where the reaction rate decreases proportionally with the thickness of the product layer, best fitted both hydriding/dehydriding kinetics. Since the same model was shown to be prevalent on the absorption kinetics of mechanically ball-milled TiFe IMC alloy, the assumption of a constant diffusion interface area for a spherical particle (as stated by Jander), although geometrically imprecise, should be considered at least a valid approximation.

Based on the preliminary results showed here for the TiFe IMC alloy with polymer processed by the cold rolling technique, polymer adhesion to the metal surface is a significant issue to be solved. Further experiments are being planned to attempt a better covering procedure.

\section{Acknowledgments}

This study was financed in part by the Coordenação de Aperfeiçoamento de Pessoal de Nível Superior - Brasil (CAPES) - Finance Code 001. PNPD20131474-33001014004P9. The authors are grateful to the Brazilian National Council for Scientific and Technological Development (CNPq, grant no. 428641/2016-4), and to the Laboratory of Structural Characterization (LCE/DEMa/UFSCar) for the use of its facilities.

\section{References}

1. Zhu HY, Wu J, Wang QD. Reactivation behaviour of TiFe hydride. J Alloys Compd. 1994;215:91-5. http://dx.doi. org/10.1016/0925-8388(94)90823-0.

2. Vega LER, Leiva DR, Leal RM No, Silva WB, Silva RA, Ishikawa TT, et al. Mechanical activation of TiFe for hydrogen storage by cold rolling under inert atmosphere. Int J Hydrogen Energy. 2018;43:2913-8. http://dx.doi.org/10.1016/j.ijhydene.2017.12.054.

3. Modi P, Aguey-Zinsou K-F. Titanium-iron-manganese (TiFe0.85Mn0.15) alloy for hydrogen storage: reactivation upon oxidation. Int J Hydrogen Energy. 2019;44:16757-64. http://dx.doi.org/10.1016/j.ijhydene.2019.05.005.

4. Vega LER, Leiva DR, Leal RM No, Silva WB, Silva RA, Ishikawa TT, et al. Improved ball milling method for the synthesis of nanocrystalline TiFe compound ready to absorb hydrogen. Int J Hydrogen Energy. 2020;45:2084-93. http:// dx.doi.org/10.1016/j.ijhydene.2019.11.035.

5. Reilly JJ, Wiswall RH. Formation and properties of iron titanium hydride. Inorg Chem. 1974;13:218-22. http://dx.doi. org/10.1021/ic50131a042.

6. Schefer J, Fischer P, Hälg W, Stucki F, Schlapbach L, Andresen AF. Structural phase transitions of FeTi-deuterides. Mater Res Bull. 1979;14:1281-94. http://dx.doi.org/10.1016/00255408(79)90005-9.

7. Chung HS, Lee JY. Hydriding and dehydriding reaction rate of FeTi intermetallic compound. Int J Hydrogen Energy. 1985; 10(78):537-42. http://dx.doi.org/10.1016/0360-3199(85)90084-9.

8. Sujan GK, Pan Z, Li H, Liang D, Alam N. An overview on TiFe intermetallic for solid-state hydrogen storage: microstructure, hydrogenation and fabrication processes. Crit Rev Solid State Mater Sci. 2020;45:410-27. http://dx.doi.org/10.1080/104084 36.2019 .1652143 . 
9. Reilly JJ. Metal hydride technology [Internet]. New York: Department of Energy and Environment, Brookhaven National Laboratory Upton; 1979. [cited 2021 Apr 29]. Available from: https://www.osti.gov/servlets/purl/6051964-uk4HQj/

10. Sandrock GD, Goodell PD. Surface poisoning of LaNi5, FeTi and $(\mathrm{Fe}, \mathrm{Mn}) \mathrm{Ti}$ by $\mathrm{O} 2$, Co and H2O. J Less Common Met. 1980;73:161-8. http://dx.doi.org/10.1016/0022-5088(80)90355-0.

11. Williams M, Lototsky MV, Davids MW, Linkov V, Yartys VA, Solberg JK. Chemical surface modification for the improvement of the hydrogenation kinetics and poisoning resistance of TiFe. J Alloys Compd. 2011;509:S770-4. http://dx.doi.org/10.1016/j. jallcom.2010.11.063.

12. Reilly JJJ, Wiswall RH. Iron titanium hwride: its formation, properties, and application [Internet]. New York: Brookhaven National Laboratory Upton; 1973 [cited 2021 Apr 29]. Available from: http://www.energymaterials.co.uk/Fe_Ti_H.pdf

13. Schober T, Westlake DG. The activation of FeTi for hydrogen storage: a different view. Scr Metall. 1981;15:913-8. http:// dx.doi.org/10.1016/0036-9748(81)90277-5.

14. Matsumoto T, Amano M. The hydriding of FeTi during an activation treatment - by in-situ X-ray diffraction -. Scr Metall. 1981;15:879-83. http://dx.doi.org/10.1016/0036-9748(81)902702.

15. Choong-Nyeon P, Jai-Young L. Kinetic properties of the hydrogenation of the FeTi intermetallic compound. J Less Common Met. 1983;91:189-201. http://dx.doi.org/10.1016/00225088(83)90312-0.

16. Schlapbach L, Riesterer T. The activation of FeTi for hydrogen absorption. Appl Phys, A Solids Surf. 1983;32:169-82. http:// dx.doi.org/10.1007/BF00820257.

17. Zaluski L, Zaluska A, Ström-Olsen J. Nanocrystalline metal hydrides. J Alloys Compd. 1997;253-254:70-9. http://dx.doi. org/10.1016/S0925-8388(96)02985-4.

18. Zadorozhnyy VY, Klyamkin SN, Kaloshkin SD, Zadorozhnyy MY, Bermesheva OV. Mechanochemical synthesis and hydrogen sorption properties of nanocrystalline TiFe. Inorg Mater. 2011;47:1081-6. http://dx.doi.org/10.1134/S0020168511100232.

19. Zadorozhnyy V, Klyamkin S, Zadorozhnyy M, Bermesheva $\mathrm{O}$, Kaloshkin S. Hydrogen storage nanocrystalline TiFe intermetallic compound: synthesis by mechanical alloying and compacting. Int J Hydrogen Energy. 2012;37:17131-6. http:// dx.doi.org/10.1016/j.ijhydene.2012.08.078.

20. Emami H, Edalati K, Matsuda J, Akiba E, Horita Z. Hydrogen storage performance of TiFe after processing by ball milling. Acta Mater. 2015;88:190-5. http://dx.doi.org/10.1016/j. actamat.2014.12.052.

21. Zadorozhnyy VY, Milovzorov GS, Klyamkin SN, Zadorozhnyy MY, Strugova DV, Gorshenkov MV, et al. Preparation and hydrogen storage properties of nanocrystalline TiFe synthesized by mechanical alloying. Prog Nat Sci Mater Int. 2017;27:14955. http://dx.doi.org/10.1016/j.pnsc.2016.12.008.

22. Nobuki T, Moriya T, Hatate M, Crivello J-C, Cuevas F, Joubert J-M. Synthesis of TiFe hydrogen absorbing alloys prepared by mechanical alloying and SPS treatment. Metals (Basel). 2018;8:264. http://dx.doi.org/10.3390/met8040264.

23. Edalati K, Akiba E, Horita Z. High-pressure torsion for new hydrogen storage materials. Sci Technol Adv Mater. 2018;19:18593. http://dx.doi.org/10.1080/14686996.2018.1435131.

24. Manna J, Tougas B, Huot J. Mechanical activation of air exposed $\mathrm{TiFe}+4 \mathrm{wt} \% \mathrm{Zr}$ alloy for hydrogenation by cold rolling and ball milling. Int J Hydrogen Energy. 2018;43:20795-800. http:// dx.doi.org/10.1016/j.ijhydene.2018.09.096.

25. Falcão RB, Dammann EDCC, Rocha CJ, Durazzo M, Ichikawa RU, Martinez LG, et al. An alternative route to produce easily activated nanocrystalline TiFe powder. Int J Hydrogen Energy. 2018;43:16107-16. http://dx.doi.org/10.1016/j.ijhydene.2018.07.027.

26. Trudeau ML, Schulz R, Zaluski L, Hosatte S, Ryan DH, Doner $\mathrm{CB}$, et al. Nanocrystalline iron-titanium alloys prepared by high-energy mechanical deformation. Mater Sci Forum. 1992;88-90:537-44. http://dx.doi.org/10.4028/www.scientific. net/MSF.88-90.537.

27. Zaluski L, Tessier P, Ryan DH, Doner CB, Zaluska A, StrömOlsen JO, et al. Amorphous and nanocrystalline Fe-Ti prepared by ball milling. J Mater Res. 1993;8:3059-68. http://dx.doi. org/10.1557/JMR.1993.3059.

28. Zaluski L, Zaluska A, Tessier P, Ström-Olsen JO, Schulz R. Hydrogen absorption by nanocrystalline and amorphous Fe-Ti with palladium catalyst, produced by ball milling. J Mater Sci. 1996;31:695-8. http://dx.doi.org/10.1007/BF00367887.

29. Jurczyk M, Jankowska E, Nowak M, Jakubowicz J. Nanocrystalline titanium-type metal hydride electrodes prepared by mechanical alloying. J Alloys Compd. 2002;336:265-9. http://dx.doi. org/10.1016/S0925-8388(01)01875-8.

30. Jurczyk M, Jankowska E, Makowiecka M, Wieczorek I. Electrode characteristics of nanocrystalline TiFe-type alloys. J Alloys Compd. 2003;354:L1-4. http://dx.doi.org/10.1016/ S0925-8388(02)01347-6.

31. Haraki T, Oishi K, Uchida H, Miyamoto Y, Abe M, Kokaji T, et al. Properties of hydrogen absorption by nano-structured FeTi alloys. Int J Mater Res. 2008;99:507-12. http://dx.doi. org/10.3139/146.101669.

32. Niemann MU, Srinivasan SS, Phani AR, Kumar A, Goswami DY, Stefanakos EK. Nanomaterials for hydrogen storage applications: a review. J Nanomater. 2008;2008:1-9. http:// dx.doi.org/10.1155/2008/950967.

33. Zadorozhnyy VY, Klyamkin SN, Kaloshkin SD, Skakov YA. Production of intermetallic compound of FeTi by means of mechanical-chemical synthesis and its interaction with hydrogen. Inorg Mater: Appl Res. 2010;1:41-5. http://dx.doi.org/10.1134/ S2075113310010065.

34. Edalati K, Matsuda J, Yanagida A, Akiba E, Horita Z. Activation of TiFe for hydrogen storage by plastic deformation using groove rolling and high-pressure torsion: similarities and differences. Int J Hydrogen Energy. 2014;39:15589-94. http:// dx.doi.org/10.1016/j.ijhydene.2014.07.124.

35. Sakintuna B, Lamari-Darkrim F, Hirscher M. Metal hydride materials for solid hydrogen storage: a review. Int J Hydrogen Energy. 2007;32:1121-40. http://dx.doi.org/10.1016/j. ijhydene.2006.11.022.

36. Checchetto R, Carotenuto G, Bazzanella N, Miotello A. Synthesis and characterization of polymer embedded LaNi 5 composite material for hydrogen storage. J Phys D Appl Phys. 2007;40:4043-8. http://dx.doi.org/10.1088/0022-3727/40/13/021.

37. Checchetto R, Bazzanella N, Miotello A, Mengucci P. H2 storage efficiency and sorption kinetics in composite materials. J Phys Chem Solids. 2008;69:2160-3. http://dx.doi.org/10.1016/j. jpcs.2008.03.032.

38. Checchetto R, Bazzanella N, Miotello A, Carotenuto G, Nicolais L. Hydrogen sorption in metal-polymer composites: the role of interfaces. J Appl Phys. 2009;105:083513. http://dx.doi. org/10.1063/1.3106583.

39. Pentimalli M, Padella F, Pilloni L, Imperi E, Matricardi P. AB5/ABS composite material for hydrogen storage. Int $\mathrm{J}$ Hydrogen Energy. 2009;34:4592-6. http://dx.doi.org/10.1016/j. ijhydene.2008.10.013.

40. Pentimalli M, Padella F, La Barbera A, Pilloni L, Imperi E. A metal hydride-polymer composite for hydrogen storage applications. Energy Convers Manage. 2009;50:3140-6. http:// dx.doi.org/10.1016/j.enconman.2009.08.021.

41. Pentimalli M, Imperi E, Zaccagnini A, Padella F. Nanostructured metal hydride - Polymer composite as fixed bed for sorption technologies. Advantages of an innovative combined approach by high-energy ball milling and extrusion techniques. Renew Energy. 2017;110:69-78. http://dx.doi.org/10.1016/j.renene.2016.07.074.

42. Zadorozhnyy MY, Klyamkin SN, Strugova DV, Olifirov LK, Milovzorov GS, Kaloshkin SD, et al. Deposition of polymer 
coating on metallic powder through ball milling: application to hydrogen storage intermetallics. Int J Energy Res. 2016;40:2739. http://dx.doi.org/10.1002/er.3461.

43. Mintz MH, Zeiri Y. Hydriding kinetics of powders. J Alloys Compd. 1995;216:159-75. http://dx.doi.org/10.1016/09258388(94)01269-N.

44. Martin M, Gommel C, Borkhart C, Fromm E. Absorption and desorption kinetics of hydrogen storage alloys. J Alloys Compd. 1996;238:193-201. http://dx.doi.org/10.1016/09258388(96)02217-7.

45. Sharp JH, Brindley GW, Narahari Achar BN. Numerical data for some commonly used solid state reaction equations. J Am Ceram Soc. 1966;49:379-82. http://dx.doi.org/10.1111/j.1151-2916.1966. tb13289.x.

46. Crank J. The mathematics of diffusion. London: Oxford University Press; 1979.

47. Neufurth M, Wang X, Wang S, Steffen R, Ackermann M, Haep $\mathrm{ND}$, et al. 3D printing of hybrid biomaterials for bone tissue engineering: calcium-polyphosphate microparticles encapsulated by polycaprolactone. Acta Biomater. 2017;64:377-88. http:// dx.doi.org/10.1016/j.actbio.2017.09.031.

48. Koga N, Criado JM. Kinetic analyses of solid-state reactions with a particle-size distribution. J Am Ceram Soc. 2005;81:2901-9. http://dx.doi.org/10.1111/j.1151-2916.1998.tb02712.x.

49. Khawam A, Flanagan DR. Solid-state kinetic models: basics and mathematical fundamentals. J Phys Chem B. 2006;110:1731528. http://dx.doi.org/10.1021/jp062746a.

50. Pang Y, Li Q. A review on kinetic models and corresponding analysis methods for hydrogen storage materials. Int J Hydrogen Energy. 2016;41:18072-87. http://dx.doi.org/10.1016/j. ijhydene.2016.08.018.

51. Lang J, Eagles M, Conradi MS, Huot J. Hydrogenation rate limiting step, diffusion and thermal conductivity in cold rolled magnesium hydride. J Alloys Compd. 2014;583:116-20. http:// dx.doi.org/10.1016/j.jallcom.2013.08.126.

52. Barkhordarian G, Klassen T, Bormann R. Kinetic investigation of the effect of milling time on the hydrogen sorption reaction of magnesium catalyzed with different $\mathrm{Nb} 2 \mathrm{O} 5$ contents. J Alloys Compd. 2006;407:249-55. http://dx.doi.org/10.1016/j. jallcom.2005.05.037.

53. Macherauch E. X-ray stress analysis. Exp Mech. 1966;6:14053. http://dx.doi.org/10.1007/BF02326143.
54. Tanaka K. Recent $x$-ray diffraction studies of metal fatigue in Japan. J Strain Anal. 1975;10:32-41. http://dx.doi. org/10.1243/03093247V101032.

55. Paul S. Prevéy, X-ray diffraction residual stress techniques. In: ASM International, editor. Materials characterization. Materials Park, OH: ASM International; 1986. p. 380-392. http://dx.doi. org/10.31399/asm.hb.v10.a0001761.

56. Paul S. Prevéy, current applications of X-Ray diffraction residual stress measurement. In: Vander Voort, G, Friel J, editors. Developments in materials characterization technologies. Materials Park, OH: ASM International; 1996. p. 103-110.

57. Ungár T. Microstructural parameters from X-ray diffraction peak broadening. Scr Mater. 2004;51:777-81. http://dx.doi. org/10.1016/j.scriptamat.2004.05.007.

58. Lv P, Guzik MN, Sartori S, Huot J. Effect of ball milling and cryomilling on the microstructure and first hydrogenation properties of $\mathrm{TiFe}+4 \mathrm{wt} \% \mathrm{Zr}$ alloy. J Mater Res Technol. 2019;8:1828-34. http://dx.doi.org/10.1016/j.jmrt.2018.12.013.

59. Lv P, Liu Z, Dixit V. Improved hydrogen storage properties of TiFe alloy by doping $(\mathrm{Zr}+2 \mathrm{~V})$ additive and using mechanical deformation. Int J Hydrogen Energy. 2019;44:27843-52. http:// dx.doi.org/10.1016/j.ijhydene.2019.08.249.

60. Jander W. Reaktionen im festen Zustande bei höheren Temperaturen. Reaktionsgeschwindigkeiten endotherm verlaufender Umsetzungen. Z Anorg Allg Chem. 1927;163:130. http://dx.doi.org/10.1002/zaac.19271630102.

61. Shao H, Xin G, Zheng J, Li X, Akiba E. Nanotechnology in Mg-based materials for hydrogen storage. Nano Energy. 2012;1:590-601. http://dx.doi.org/10.1016/j.nanoen.2012.05.005.

62. Muthukumar P, Satheesh A, Linder M, Mertz R, Groll M. Studies on hydriding kinetics of some La-based metal hydride alloys. Int J Hydrogen Energy. 2009;34:7253-62. http://dx.doi. org/10.1016/j.ijhydene.2009.06.075.

63. Chou K-C, Xu K. A new model for hydriding and dehydriding reactions in intermetallics. Intermetallics. 2007;15:767-77. http://dx.doi.org/10.1016/j.intermet.2006.10.004.

64. de Almeida GR No, Gonçalves Beatrice CA, Leiva DR, Pessan LA. Polymer-based composite containing nanostructured LaNi5 for hydrogen storage: improved air stability and processability. Int J Hydrogen Energy. 2020. http://dx.doi.org/10.1016/j. ijhydene.2020.03.069. 